\title{
Hematological Profile of HIV-Infected Patients on First-Line Highly Active Antiretroviral Therapy and Its Correlation With CD4 Count
}

\author{
John Jospeh Diamond Princy ${ }^{1} \quad$ Kshetrimayum Birendra Singh ${ }^{1} \quad$ Ningthoujam Biplab ${ }^{1}$ \\ Ningthoukhongjam Reema ${ }^{1}$ Rajesh Boini ${ }^{1}$ Ajay Gowde ${ }^{1}$
}

\author{
1Department of Medicine, Regional Institute of Medical Sciences, \\ Imphal, Manipur, India
}

Int J Recent Surg Med Sci 2021;7:54-63.

\begin{abstract}
Address for correspondence Ningthoukhongjam Reema, MBBS, MD, PGDGM, CCEBDM, Senior Resident, Department of Medicine, Regional Institute of Medical Sciences, Imphal 795004, Manipur, India (e-mail: thangjamreema@gmail.com).
\end{abstract}

\begin{abstract}
Keywords

- anemia

- CD4 count

- cytopenia

- HAART

- HIV

Introduction Human immunodeficiency virus (HIV) infection is a state of profound immunodeficiency. Disorders of hematopoietic system are a common but often overlooked complication of HIV infection. This can manifest at any stage of the disease but more commonly in the advanced stage with low CD4 count. Anemia is the most common hematological abnormality in HIV patients and prevalence ranges from 1.3 to $95 \%$. As HIV disease progresses, the prevalence and severity of anemia also increase. Hence, this study was undertaken to assess the hematological parameters of HIV-infected patients on highly active antiretroviral therapy (HAART) at different treatment durations with the hope to improve the HAART outcome in HIV patients and its correlation with CD4 count.

Methods This prospective longitudinal study enrolled $134 \mathrm{HIV}$-infected patients admitted to or attending the OPD in the Department of Medicine or Antiretroviral Therapy (ART) Center (Center of Excellence), Regional Institute of Medical Sciences (RIMS), Imphal, Manipur, from 2018 to 2020. Complete hemogram, CD4 count, and other related-blood investigations were studied.

Results The mean age of the study population was $39.9 \pm 11.04$ years. Of the 134 patients, 75 (56\%) were males and 59 (44\%) were females. Twelve (9\%) patients had a history of injecting drug use (IDU). TLE (tenofovir, lamivudine, efavirenz) regimen was started on $112(83.6 \%)$ patients and the majority of them (69/134 [51.5\%]) had a CD4 count of 200 to 499 cells $/ \mathrm{mm}^{3}$, which increased significantly 6 months after HAART to 99 to 1,149 cells $/ \mathrm{mm}^{3}$, with a mean of $445 \pm 217$ cells $/ \mathrm{mm}^{3}$. There were significant improvements in hemoglobin $(\mathrm{Hb})$ levels, total leukocyte count (TLC), absolute neutrophil count (ANC), and absolute lymphocyte count (ALC) after HAART indicating a positive correlation with CD4 count $(p<0.05)$. Thrombocytopenia was observed higher after HAART when compared to baseline. There was a positive correlation between platelet count and CD4 count. However, the mean corpuscular
\end{abstract}

published online June 3, 2021
DOI https://doi.org/

$10.1055 / \mathrm{s}-0041-1730257$

ISSN 2455-7420
C 2021. Medical and Surgical Update Society.

This is an open access article published by Thieme under the terms of the Creative Commons Attribution-NonDerivative-NonCommercial-License, permitting copying and reproduction so long as the original work is given appropriate credit. Contents may not be used for commercial purposes, or adapted, remixed, transformed or built upon. (https://creativecommons.org/licenses/by-nc-nd/4.0/).

Thieme Medical and Scientific Publishers Pvt. Ltd. A-12, 2nd Floor, Sector 2, Noida-201301 UP, India 
volume (MCV) and erythrocyte sedimentation rate (ESR) had a negative correlation with CD4 count.

Conclusion The study inferred a strong positive correlation between CD4 and Hb levels, TLC, ANC, ALC, and platelet count after HAART with improvement in these values as CD4 count increases. Specific treatment intervention based on the changes in the immunohematological profile trends can help prevent most of the adverse effects on HIV patients in our community.

\section{Introduction}

Human immunodeficiency virus (HIV) infection is a state of profound immunodeficiency, encompassing the spectrum of diseases ranging from acute syndrome seen with primary infection and prolonged asymptomatic state to an advanced disease or full-blown acquired immunodeficiency syndrome (AIDS). Hematopoietic system disorders are common but often overlooked complications of HIV infection. They can manifest at any stage of the disease and include anemia, leucopoenia, thrombocytopenia, hemophagocytic syndrome, AIDS-related lymphoma, and rarely thromboembolism. ${ }^{1}$

Peripheral blood cytopenia and immune paresis are common in HIV infection and increase in frequency with advancing disease. In both antiretroviral-treated and untreated individuals, different types of hematological abnormalities are common. ${ }^{2}$ Anemia is the most common hematological abnormality in HIV patients and prevalence ranges from 1.3 to $95 \%$. Normocytic normochromic anemia is the predominant type followed by microcytic anemia. The causes include chronic disease, opportunistic infections, nutritional deficiencies, and drug toxicities. As HIV disease progresses, the prevalence and severity of anemia also increase. ${ }^{3-6}$

Thrombocytopenia is the second most frequent hematological complication of HIV infection (3-40\% of individuals) occurring at any stage of HIV infection. Chronic infection with HIV is now a well-characterized cause of chronic immune thrombocytopenic purpura. ${ }^{3,4}$ The possible mechanisms that have been reported are immune-mediated destruction of platelets by antibodies and cross-reacting antibodies that are directed toward HIV proteins, particularly gp120 and p24. This type of platelet destruction is called immune thrombocytopenic purpura, which is characterized by very low platelet counts with normal hematocrit and white blood cell count.,

Neutropenia is the most common leukopenia occurring in individuals with advanced HIV infection (10-30\%). ${ }^{3}$ HIV infection suppresses the bone marrow (BM) and leads to decreased levels of granulocyte colony-stimulating factor, which stimulates production of white blood cells (WBC) in the BM and affects the granulocyte-macrophage lineage, resulting in leukopenia and neutropenia. Also, myelosuppressive drugs or other opportunistic infections including cytomegalovirus, tuberculosis (TB), and histoplasmosis may cause leucopoenia. HIV infection can directly result in lymphopenia as infection progresses, leading to a decrease in CD4+ lymphocytes. ${ }^{3,4}$
Hematological parameters are important monitoring tools for assessing treatment and prognosis in HIV. The use of antiretroviral drugs could positively or negatively affect these parameters, depending on the choice of combination used. Although many drugs used for the treatment of HIV-related disorders are myelosuppressive, severe cytopenia is associated with the use of zidovudine. In general, patients with advanced disease are more likely to have haematologic toxic effects possibly due to reduced marrow reserves. ${ }^{5}$

A thorough assessment of the patient's hematological profile is central to the clinician's informed choice of an appropriate antiretroviral regimen and overall patient care. ${ }^{7}$ Though some studies on immunological and hematological parameters of HIV patients on highly active antiretroviral therapy (HAART) have been carried out, comparative studies on other immunohematological parameters at specific time duration of treatment with HIV-positive patients in our country are scarce. Therefore, we assessed the hematological parameters of HIV-positive patients on HAART at different treatment durations with the hope to improve the HAART outcome in HIV patients and its correlation with CD4 count.

\section{Materials and Methods}

This prospective longitudinal study enrolled 134 diagnosed cases of HIV infection admitted to or attending the OPD in the Department of Medicine or Antiretroviral Therapy Center (Center of Excellence), Regional Institute of Medical Sciences (RIMS), Imphal, Manipur, from 2018 to 2020.

\section{Inclusion Criteria}

1. All diagnosed cases of HIV infection, aged 18 years and above,

2. HIV patients who were not on HAART at the start of study, and

3. Those who had a CD4 cell count done within 4 weeks prior to the start of the study were included in the study.

\section{Exclusion Criteria}

Patients who were previously diagnosed with hematological malignancies, hemoglobinopathies (thalassemia, sickle cell anemia, etc.), and other hematological disorders, co-infection with hepatitis B virus (HBV) and hepatitis C virus (HCV) at the start of study, severely ill patients, pregnant women, and those not giving consent were excluded from the study. 


\section{Study Procedure}

A detailed history of presenting symptoms, past and personal, was recorded in proper pro forma along with age, sex, marital status, history of injecting drug use (IDU), hypertension (HTN), diabetes mellitus (DM), drug history, and CD4 count of HIV-infected patients before HAART and 6 months after initiation of first-line HAART. Investigations like complete blood count (CBC), hepatitis B surface antigen ( $\mathrm{HBsAg}$ ), Anti-HCV $\mathrm{Ab}$, and chest $\mathrm{X}$-ray (if indicated) were done. A detailed relevant clinical examination of every subject was also done.

\section{Study Tools}

1. HIV was diagnosed as per the National Aids Control Organization (NACO) guidelines using enzyme-linked immunosorbent assay (ELISA)/rapid kit.

2. Hematological parameters were determined using the SYSMEX XS-800i^67618 hematology analyzer (Transasia, Kobe, Japan).

3. Anemic patients were classified into three groups based on severity similar to Shah and Anudhakar. ${ }^{8}$ Hemoglobin $(\mathrm{Hb})$ level of 10 to $10.9 \mathrm{~g} / \mathrm{dL}$ was considered mild, 7 to $9.9 \mathrm{~g} / \mathrm{dL}$ moderate, and less than $7 \mathrm{~g} / \mathrm{dL}$ severe.

4. A leucocyte count less than 4,000 cells $/ \mathrm{mm}^{3}$ was considered leucopenia, 4,000 to 11,000 cells $/ \mathrm{mm}^{3}$ normal, and greater than 11,000 cells $/ \mathrm{mm}^{3}$ leucocytosis.

5. Neutropenia was defined as when absolute neutrophil counts (ANC) were less than 1,500 cells $/ \mathrm{mm}^{3}$, which were further classified as mild $\left(1,000-1,499\right.$ cells $\left./ \mathrm{mm}^{3}\right)$, moderate (500-999 cells $\left./ \mathrm{mm}^{3}\right)$, and severe neutropenia $\left(<500\right.$ cells $\left./ \mathrm{mm}^{3}\right)$.

6. Lymphopenia was defined as absolute lymphocyte count (ALC) less than 1,000 cells $/ \mathrm{mm}^{3}$.

7. Thrombocytopenia was defined as when platelets counts were less than 150,000 cells $/ \mathrm{mm}^{3}$, further classified as mild $\left(100,000-149,000\right.$ cells $\left./ \mathrm{mm}^{3}\right)$, moderate $\left(50,000-99,999\right.$ cells $\left./ \mathrm{mm}^{3}\right)$, and severe (less than 50,000 cells $/ \mathrm{mm}^{3}$ ) thrombocytopenia.

8. mean corpuscular volume (MCV) of 80 to $100 \mathrm{fL}$ was considered normal, less than $80 \mathrm{fL}$ low, and greater than $100 \mathrm{fL}$ high.

9. ESR value less than $20 \mathrm{~mm} / \mathrm{h}$ was considered normal and $\geq 20 \mathrm{~mm} / \mathrm{h}$ as high.

10. The immunological $C D 4+T$ cells were assayed using the FACSCount SV Version 1.3 at RIMS.

11. According to the Centers for Disease Control and Prevention (CDC) staging system, patients were classified into three groups based on CD4 counts. A CD4 count greater than 500 cells $/ \mathrm{mm}^{3}$ was considered stage 1, 200 to 499 cells $/ \mathrm{mm}^{3}$ stage 2 , and less than 200 cells $/ \mathrm{mm}^{3}$ stage 3 .

\section{Statistical Software}

IBM SPSS Statistics 21 (IBM Corp., Armonk, NY, United States) developer (statistical package for the social sciences software) was used for analysis of data. The categorical data were presented as number or mean or percentage, whereas continuous data were presented as mean and median. Student's $t$-test and Pearson's correlation coefficient were used for analysis, and $p$-value less than 0.05 was considered significant.

\section{Approval of Research Ethics Board and Informed Consent}

The study was approved by Research Ethics Board Regional Institute of Medical Sciences, Imphal (REB No: A/206/REB Comm (SP)/RIMS/2015/417/35/2018).

\section{Results}

A total of 134 HIV-positive patients were enrolled for the study. The mean age of the study population was $39.9 \pm$ 11.04 years, with the majority (46 [34.5\%]) in the age group of 40 to 49 years. There were 75 (56\%) males and 59 (44\%) females, and most of them (109 [81.3\%]) were already married at the start of the study. Twelve (9\%) patients had a history of IDU. TLE (tenofovir, lamivudine, efavirenz) regimen was started in 112 (83.6\%) patients, followed by ZLN (zidovudine, lamivudine, nevirapine) in $16(11.9 \%)$ patients, ALE (abacavir, lamivudine, efavirenz) in $5(3.7 \%)$ patients, and ZLE (zidovudine, lamivudine, efavirenz) in $1(0.7 \%)$ patient. The majority of them (69/134 [51.5\%]) had a CD4 count of 200 to 499 cells $/ \mathrm{mm}^{3}, 53$ (39.6\%) patients had a CD4 count of greater than 500 cells $/ \mathrm{mm}^{3}$, and $12(9 \%)$ patients had less than 200 cells $/ \mathrm{mm}^{3}$. Six months after HAART, the CD4 count increased at a range of 99 to 1,149 cells/ $/ \mathrm{mm}^{3}$, with a mean of $445 \pm 217$, which was found to be statistically significant $(p<0.05 ;$ - Table 1$)$.

$\mathrm{Hb}$ levels of HIV patients before HAART in the study ranged from 4.7 to $15.8 \mathrm{~g} / \mathrm{dL}$ with most of them having $\mathrm{Hb}$ levels less than $11 \mathrm{~g} / \mathrm{dL}$. Mean $\mathrm{Hb}$ values at baseline and 6 months after HAART were $10.87 \pm 2.41$ and $11.40 \pm$ $2.18 \mathrm{~g} / \mathrm{dL}$, respectively, with a mean difference of -0.5366 . There was an increase in Hb level after HAART, which was statistically significant $(p<0.05)$. Before HAART, 51.5\% (69) of the study population had normal Hb values, $29.1 \%$ (39) had mild anemia, 12.7\% (17) had moderate anemia, and $6.7 \%$ (9) had severe anemia. Six months after HAART, $62.7 \%$ (84) of the study population improved to normal $\mathrm{Hb}$ levels, $22.4 \%$ (30) had mild anemia, 11.9\% (16) had moderate anemia, and 3\% (4) had severe anemia (-Fig. 1). Six months after HAART, the number of patients with anemia decreased from 65 (49.5\%) to 50 . Of these, the number of patients with normocytic anemia reduced from 34.6 to $23 \%$, microcytic anemia from 14.9 to $12 \%$, and 12 patients had macrocytosis after the start of therapy ( - Fig. 2). Distribution of different types of anemia according to the HAART regimes is given in - Table 2. Six months after HAART, the number of patients who had leukopenia at baseline decreased from 17 (12.7\%) to $13(9.7 \%)$, whereas the number of patients who had leucocytosis at baseline reduced from 9 (6.7\%) to $2(1.5 \%)$, but it was not statistically significant $(p>0.05$; - Fig. 3$)$. Regarding ANC, after 6 months of HAART, the number of patients with mild neutropenia reduced from 7 (5.20\%) to only 5 patients, and the number of patients who had moderate neutropenia decreased from 4 (3\%) to 2 patients. There were no patients with severe neutropenia at baseline 
Table 1 Frequencies of patients according to different HAART regimen $(N=134)$

\begin{tabular}{|c|c|c|c|c|}
\hline \multirow[t]{2}{*}{ Variables } & \multicolumn{4}{|c|}{ ART regimen } \\
\hline & TLE & ALE & ZLN & ZLE \\
\hline \multicolumn{5}{|l|}{ Sex } \\
\hline Male & 63 & 4 & 7 & 1 \\
\hline Female & 49 & 1 & 9 & 0 \\
\hline \multicolumn{5}{|l|}{ Hemoglobin } \\
\hline Normal & 72 & 3 & 9 & 0 \\
\hline Anemia & 40 & 2 & 7 & 1 \\
\hline \multicolumn{5}{|l|}{ TLC } \\
\hline Normal & 89 & 5 & 14 & 0 \\
\hline Leucopenia & 16 & 0 & 2 & 1 \\
\hline Leucocytosis & 7 & 0 & 0 & 0 \\
\hline \multicolumn{5}{|l|}{ ANC } \\
\hline Normal & 105 & 5 & 16 & 1 \\
\hline Neutropenia & 7 & 0 & 0 & 0 \\
\hline \multicolumn{5}{|l|}{ ALC } \\
\hline Normal & 105 & 5 & 16 & 0 \\
\hline Lymphopenia & 7 & 0 & 0 & 1 \\
\hline \multicolumn{5}{|l|}{ Platelets } \\
\hline Normal & 92 & 5 & 15 & 0 \\
\hline Thrombocytopenia & 20 & 0 & 0 & 1 \\
\hline \multicolumn{5}{|l|}{ MCV } \\
\hline Normal & 94 & 4 & 9 & 0 \\
\hline High & 5 & 0 & 6 & 1 \\
\hline Low & 13 & 1 & 1 & 0 \\
\hline \multicolumn{5}{|l|}{ PBS } \\
\hline NCNC & 97 & 4 & 5 & 0 \\
\hline $\mathrm{MCHC}$ & 11 & 1 & 0 & 0 \\
\hline Macrocytosis & 4 & 0 & 6 & 1 \\
\hline \multicolumn{5}{|l|}{ CD4 count } \\
\hline$>500$ & 35 & 0 & 8 & 0 \\
\hline $300-499$ & 66 & 5 & 7 & 1 \\
\hline$<299$ & 11 & 0 & 1 & 1 \\
\hline
\end{tabular}

Abbreviations: ALC, absolute leukocyte count; ALE, abacavir, lamivudine, efavirenz; ANC, absolute neutrophil count; ART, antiretroviral therapy; HAART, highly active antiretroviral therapy; MCHC; mean corpuscular hemoglobin concentration; MCV, mean corpuscular volume; NCNC, normocytic normochromic; PBS, phosphate buffer saline; TLC, total leukocyte count; TLE, tenofovir, lamivudine, efavirenz; ZLE, zidovudine, lamivudine, efavirenz; ZLN, zidovudine, lamivudine, nevirapine.

and there was a significant decrease in ANC values after HAART ( $p<0.05$; - Fig. 4). Lymphopenia was found to be higher in patients with CD4 count less than 299 cells $/ \mathrm{mm}^{3}$. The mean ALC was 1,880.34 \pm 854.95 and 1,940 \pm 767.34 , respectively, before and after HAART, with a mean difference of -59.67 , which was statistically not significant $(p>0.05$; - Fig. 5).

In this study, 15 (\%11.3) and 22 (16.5\%) patients had thrombocytopenia before and after HAART, respectively (-Fig. 6). After HAART, the mean ALC and platelet count increased, but were statistically not significant $(p>0.05)$. However, there was a significant increase in the MCV values and CD4 count and a significant decrease in ESR after HAART ( $p<0.05$; - Table 3).

Hematological parameters like $\mathrm{Hb}$, total leukocyte count (TLC), ANC, ALC, and platelet count have shown a positive correlation with CD4 count, both at baseline and 6 months after HAART, suggesting a significant increase in TLC, ANC, and ALC $(p<0.05)$ with increase in CD4 count ( - Table 4$)$. On the other hand, MCV and ESR had a negative correlation with CD4 count; as CD4 increased, MCV and ESR decreased.

Opportunistic infections were commonly seen with CD4 counts less than 299 cells $/ \mathrm{mm}^{3} ; 8$ patients had oral candidiasis, 4 had tuberculosis (TB) and 4 had pneumocystis 


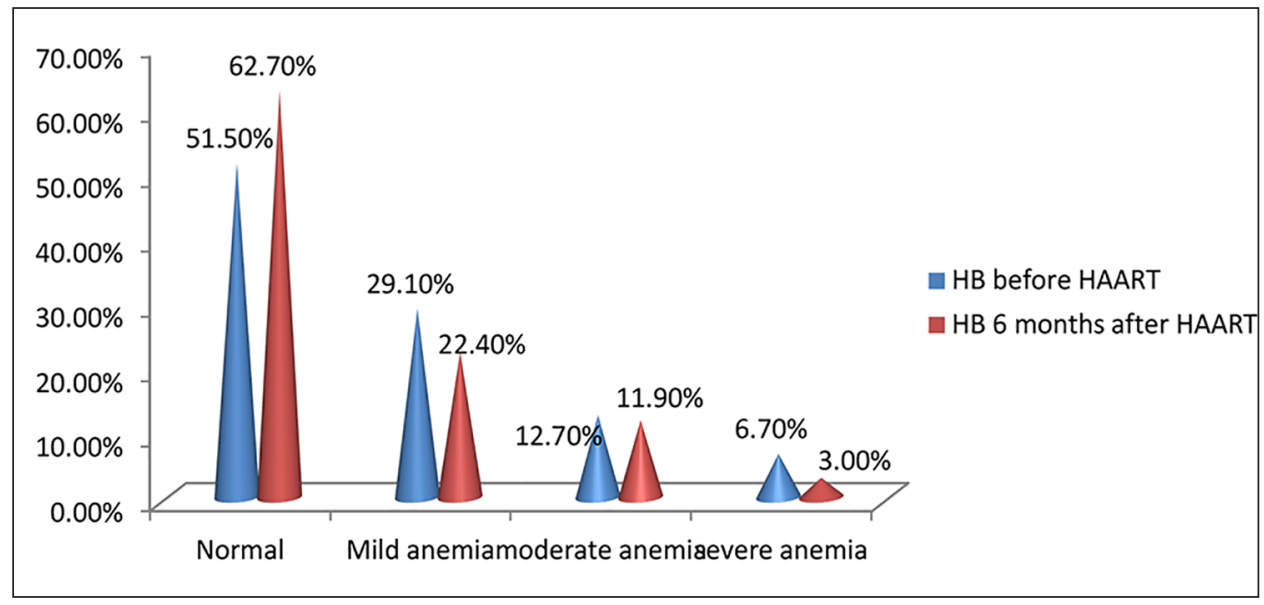

Fig. 1 Distribution of HIV-infected patients according to severity of anemia, before and 6 months after highly active antiretroviral therapy (HAART; $N=134)$.

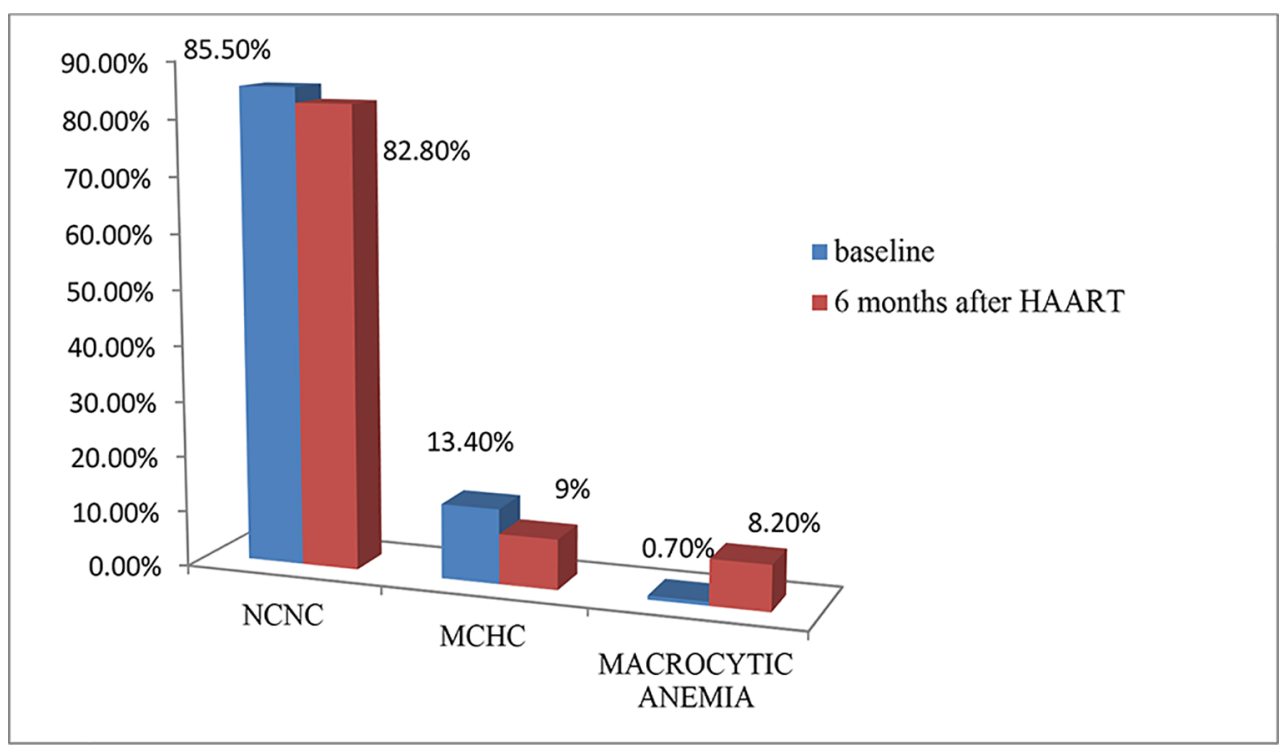

Fig. 2 Percentage of HIV-infected patients with types of anemia before and after highly active antiretroviral therapy (HAART; $N=134)$.

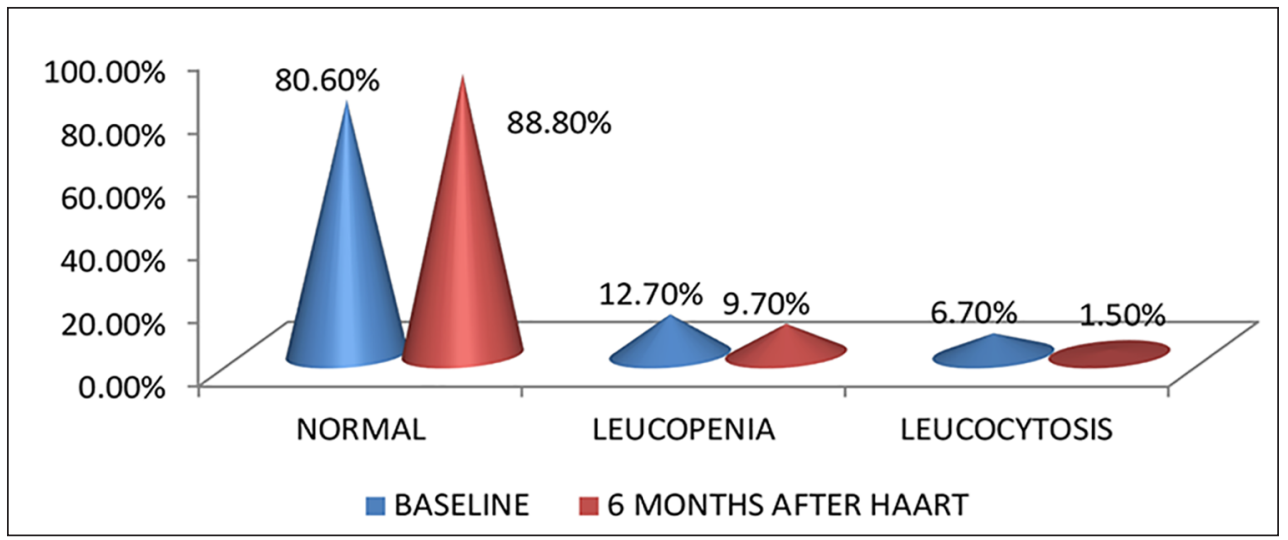

Fig. 3 Percentage of HIV-infected patients with leukopenia and leucocytosis $(N=134)$. 
Table 2 Distribution of type of anemia according to HAART regimen $(N=134)$

\begin{tabular}{|c|c|c|c|c|c|c|}
\hline \multirow[t]{2}{*}{ ART regimen } & \multirow[t]{2}{*}{ PBS } & \multicolumn{4}{|c|}{ Hb 6 mo after HAART } & \multirow[t]{2}{*}{ Total } \\
\hline & & Severe anemia & $\begin{array}{l}\text { Moderate } \\
\text { anemia }\end{array}$ & Mild anemia & Normal & \\
\hline \multirow[t]{4}{*}{ TLE } & NCNC & 4 & 7 & 18 & 68 & 97 \\
\hline & $\mathrm{MCHC}$ & 0 & 5 & 4 & 2 & 11 \\
\hline & Macrocytic & 0 & 1 & 1 & 2 & 4 \\
\hline & Total & 4 & 13 & 23 & 72 & 112 \\
\hline \multirow[t]{3}{*}{ ALE } & NCNC & 0 & 0 & 1 & 3 & 4 \\
\hline & $\mathrm{MCHC}$ & 0 & 0 & 1 & 0 & 1 \\
\hline & Total & & & 2 & 3 & 5 \\
\hline \multirow[t]{3}{*}{ ZLN } & NCNC & 0 & 2 & 1 & 7 & 10 \\
\hline & Macrocytic & 0 & 0 & 4 & 2 & 6 \\
\hline & Total & & 2 & 5 & 9 & 16 \\
\hline \multirow[t]{2}{*}{ ZLE } & Macrocytic & 0 & 1 & 0 & 0 & 1 \\
\hline & Total & & 1 & & & 1 \\
\hline \multirow[t]{4}{*}{ Overall summary } & NCNC & 4 & 9 & 20 & 78 & 111 \\
\hline & $\mathrm{MCHC}$ & 0 & 5 & 5 & 2 & 12 \\
\hline & Macrocytic & 0 & 2 & 5 & 4 & 11 \\
\hline & Total & 4 & 16 & 30 & 84 & 134 \\
\hline
\end{tabular}

Abbreviations: ALE, abacavir, lamivudine, efavirenz; ART, antiretroviral therapy; HAART, highly active antiretroviral therapy; Hb, hemoglobin; MCHC; mean corpuscular hemoglobin concentration; NCNC, normocytic normochromic; PBS, phosphate buffer saline; TLE, tenofovir, lamivudine, efavirenz; ZLE, zidovudine, lamivudine, efavirenz; ZLN, zidovudine, lamivudine, nevirapine.

Table 3 Comparison of hematological parameters at baseline and 6 months after HAART $(N=134)$

\begin{tabular}{|c|c|c|c|c|c|}
\hline Variables & Tests & Mean \pm SD & Mean difference & $95 \% \mathrm{Cl}$ & $p$-value \\
\hline \multirow[t]{2}{*}{ Hemoglobin } & $1^{\mathrm{a}}$ & $10.87 \pm 2.41$ & \multirow[t]{2}{*}{-0.5366} & \multirow[t]{2}{*}{$(-0.96,-0.10)$} & \multirow[t]{2}{*}{0.015} \\
\hline & $2^{\mathrm{b}}$ & $11.40 \pm 2.18$ & & & \\
\hline \multirow[t]{2}{*}{ TLC } & $1^{\mathrm{a}}$ & $7,080 \pm 5,942.24$ & \multirow[t]{2}{*}{947.149} & \multirow[t]{2}{*}{$(-42.68,1,936.98)$} & \multirow[t]{2}{*}{0.061} \\
\hline & $2^{\mathrm{b}}$ & $6,133 \pm 1,930$ & & & \\
\hline \multirow[t]{2}{*}{ ANC } & $1^{\text {a }}$ & $4,220.75 \pm 2,262.15$ & \multirow[t]{2}{*}{545.19} & \multirow[t]{2}{*}{$(123.93,966.45)$} & \multirow[t]{2}{*}{0.012} \\
\hline & $2^{\mathrm{b}}$ & $3,675.56 \pm 1,542.44$ & & & \\
\hline \multirow[t]{2}{*}{ ALC } & $1^{\text {a }}$ & $1,880.34 \pm 854.95$ & \multirow[t]{2}{*}{-59.67} & \multirow[t]{2}{*}{$(-211.49,92.14)$} & \multirow[t]{2}{*}{0.438} \\
\hline & $2^{\mathrm{b}}$ & $1,940 \pm 767.34$ & & & \\
\hline \multirow[t]{2}{*}{ Platelets } & $1^{\mathrm{a}}$ & $197,991.04 \pm 58,985.7$ & \multirow[t]{2}{*}{$-4,214.17$} & \multirow[t]{2}{*}{$(-16,591.79,8,163.43)$} & \multirow[t]{2}{*}{0.502} \\
\hline & $2^{\mathrm{b}}$ & $202,205.22 \pm 75,219$ & & & \\
\hline \multirow[t]{2}{*}{ MCV } & $1^{\mathrm{a}}$ & $84.92 \pm 9.87$ & \multirow[t]{2}{*}{-4.63} & \multirow[t]{2}{*}{$(-7.21,-2.05)$} & \multirow[t]{2}{*}{0.001} \\
\hline & $2^{\mathrm{b}}$ & $89.55 \pm 10.54$ & & & \\
\hline \multirow[t]{2}{*}{ ESR } & $1^{\mathrm{a}}$ & $59.99 \pm 38$ & \multirow[t]{2}{*}{8.49} & \multirow[t]{2}{*}{$(2.03,14.95)$} & \multirow[t]{2}{*}{0.010} \\
\hline & $2^{\mathrm{b}}$ & $51.49 \pm 31.89$ & & & \\
\hline \multirow[t]{2}{*}{ CD4 count } & $1^{\mathrm{a}}$ & $266.01 \pm 204.14$ & \multirow[t]{2}{*}{-179.261} & \multirow[t]{2}{*}{$(-215.96,142.87)$} & \multirow[t]{2}{*}{0.00} \\
\hline & $2^{\mathrm{b}}$ & $445.28 \pm 217.30$ & & & \\
\hline
\end{tabular}

Abbreviations: ALC, absolute lymphocyte count; ANC, absolute neutrophil count; $\mathrm{Cl}$, confidence interval; ESR, erythrocyte sedimentation rate; HAART, highly active antiretroviral therapy; MCV, mean corpuscular volume; SD, standard deviation; TLC, total leukocyte count. a Corresponds to values at baseline.

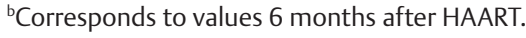




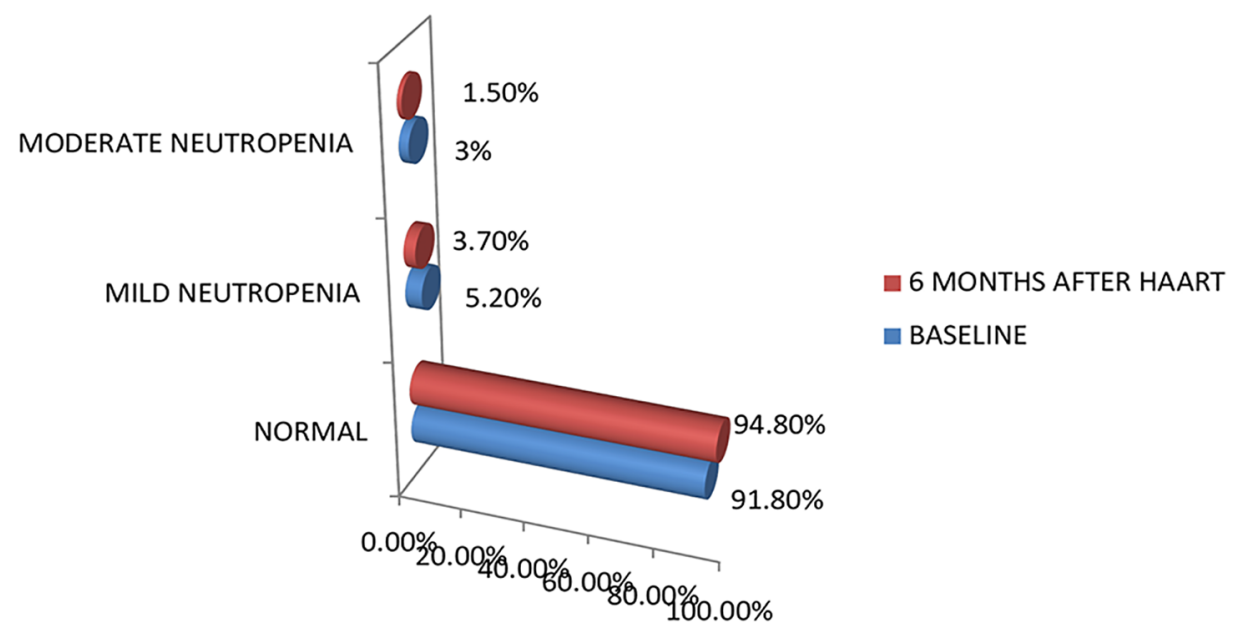

Fig. 4 Percentage of HIV-infected patients with severity of neutropenia $(N=134)$.

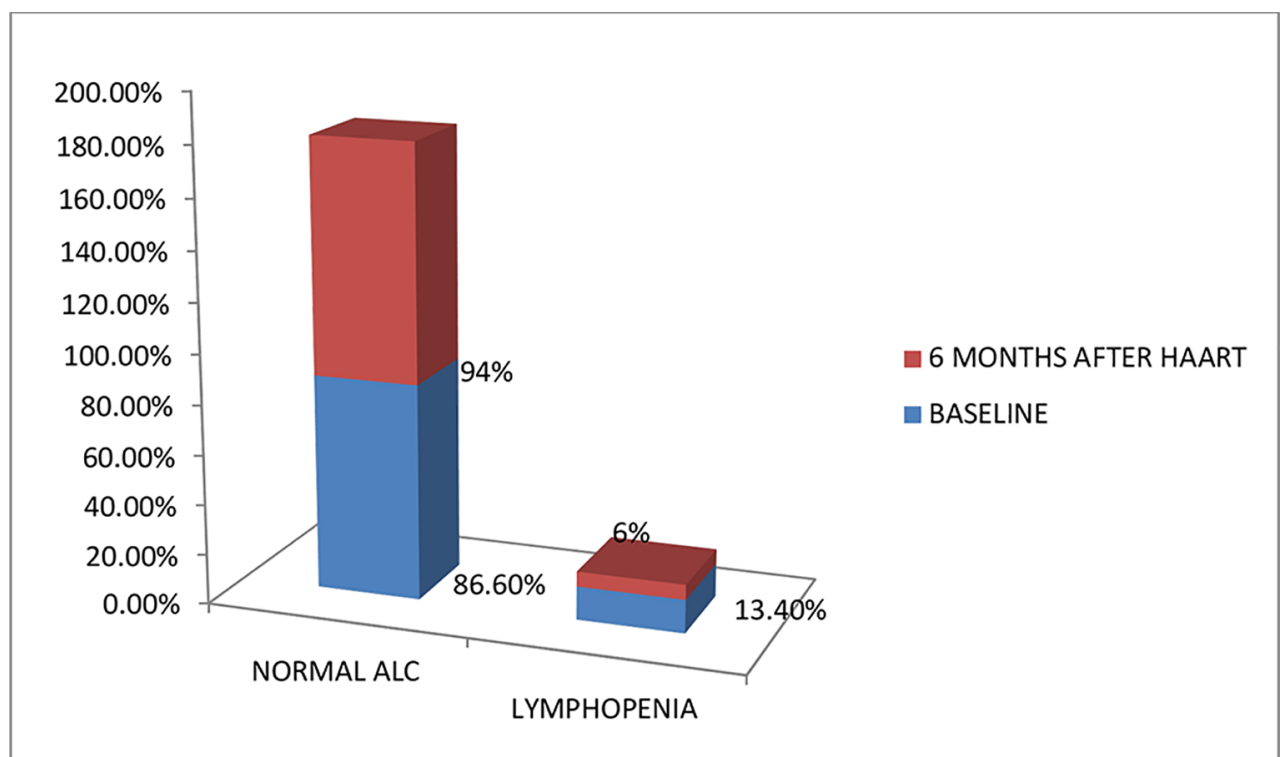

Fig. 5 Percentage of study population with lymphopenia before and after highly active antiretroviral therapy (HAART; $N=134)$.

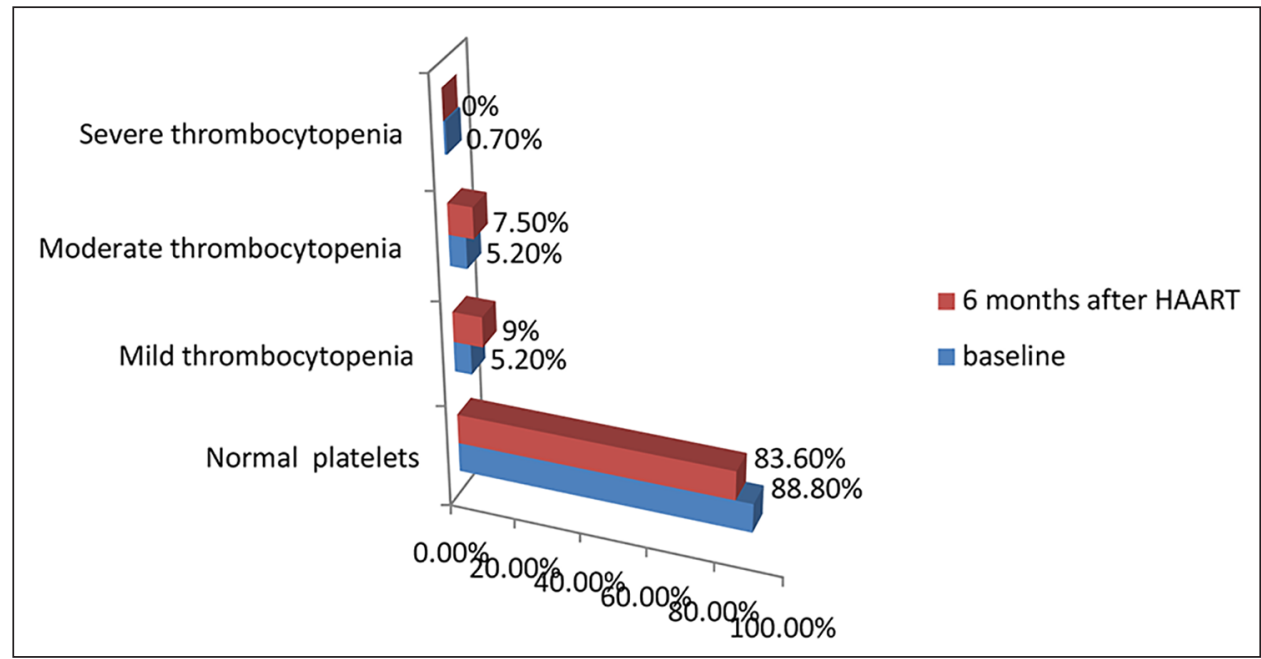

Fig. 6 Distribution of HIV-infected patients according to severity of thrombocytopenia before and after highly active antiretroviral therapy (HAART; $N=134$ ). 
Table 4 Correlation between hematological profiles with CD4 count at baseline and 6 months after HAART $(N=134)$

\begin{tabular}{|l|l|l|l|l|}
\hline \multirow{2}{*}{ Variables vs. CD4 } & \multicolumn{2}{|c|}{ Pearson's correlation } & \multicolumn{2}{c|}{$p$-value } \\
\cline { 2 - 5 } & Baseline & After 6 mo & Baseline & After 6 mo \\
\hline Hemoglobin & 0.11 & 0.119 & 0.206 & 0.17 \\
\hline TLC & 0.09 & 0.296 & 0.302 & 0.001 \\
\hline ANC & 0.283 & 0.215 & 0.001 & 0.012 \\
\hline ALC & 0.325 & 0.329 & 0.00 & 0.00 \\
\hline Platelets & 0.91 & 0.43 & 0.296 & 0.625 \\
\hline MCV & -0.030 & 0.112 & 0.731 & 0.199 \\
\hline ESR & -0.099 & -0.104 & 0.257 & 0.231 \\
\hline
\end{tabular}

Abbreviations: ALC, absolute lymphocyte count; ANC, absolute neutrophil count; ESR, erythrocyte sedimentation rate; HAART, highly active antiretroviral therapy; MCV, mean corpuscular volume; TLC, total leukocyte count.

pneumonia (PCP), and 3 patients had cryptococcal meningitis. Only 9 members had a history of DM, 4 (3\%) had HTN, and $8(6 \%)$ had renal impairment at baseline, who needed regimens other than TLE.

\section{Discussion}

In our study, $49.5 \%$ of patients had anemia, whereas in a study by Wankah et al, ${ }^{9}$ anemia was present in $62.9 \%$ cases, which may be due to racial disparity and difference in the male-to-female ratio. ${ }^{10}$ Our observations were in concordance with the findings of Assefa et $\mathrm{al}^{11}$ and Semba and Gray et al. ${ }^{12}$ Anemia, especially mild anemia of normocytic normochromic type, was the most common hematological abnormality associated with HIV infection in our study, which was similarly described by Sullivan et al. ${ }^{13}$ Six months after HAART, there was a significant increase in Hb levels $(p=0.015)$. Anemia was found to be more prevalent in patients with CD4 counts less than 299 cells $/ \mathrm{mm}^{3}$ before HAART, indicating that prevalence of anemia increases as CD4 count decreases.

The most common cause of anemia in people living with HIV (PLHIV) was BM suppression by HIV infection and use of drugs like zidovudine. ${ }^{14}$ Other causes like autoimmune antibodies to hematopoietic precursors, opportunistic infections like cytomegalovirus (CMV), B19 parvovirus, or Mycobacterium avium-intracellular (MAC) suppressing erythropoiesis, hemolytic anemia, anemia related to gastrointestinal bleeding, decreased erythropoietin levels, nutritional anemia due to B12, and iron deficiency resulting from malabsorption or malnutrition have also been stated.

Predictive factors for severe anemia after starting antiretroviral medications were female sex, baseline anemia, low CD4 count, and low body mass index (BMI) in a study conducted by Firnhaber et al. ${ }^{15}$ There are several proposed mechanisms of interruption of hematopoiesis through disruption of several cytokine mechanisms by HIV infection of BM stromal cells and macrophages. ${ }^{12}$

In our study, we found that the mean TLC before and after HAART was 7,080 $\pm 5,942.24$ and $6,133 \pm 1,930$, respectively, with a mean difference of 947.14 representing a decline in TLC values after HAART, but it was not statistically significant $(p>0.05)$. There was a positive correlation of WBC count with CD4 count, and there was improvement in the WBC counts with increase in CD4 count. Keshava and Manjunath ${ }^{16}$ concluded that there was a highly significant correlation between CD4 count and TLC ( $p$-value <0.05), which is comparable with our study. TLC can be used as an effective laboratory tool to monitor disease progression in HIV-infected persons where CD4 is not available and in resource-poor countries.

The mean ANC values were 4,220.75 \pm 2,262.15 before HAART and 3,675.56 \pm 1,542.44 6 months after HAART, with a mean difference of 545.19. There was a significant decrease in ANC values in HIV patients after HAART $(p<0.05)$ and also had a positive correlation with CD4 count. Several mechanisms for neutropenia in HIV infection have been proposed, including decreased production of granulocyte colony-stimulating factor (G-CSF), a soluble inhibitory substance that decreases neutrophil production and autoimmunity. ${ }^{17}$ Neutropenia was observed in $21 \%$ of patients prior to starting co-trimoxazole prophylaxis in a study conducted by Toure et al. ${ }^{18}$ For ALC, the mean values were 1,880.34 \pm 854.95 before HAART and 1,940 \pm 767.34 after HAART, with a mean difference of -59.67 , which was statistically not significant $(p>0.05)$. The mean \pm SD of TLC for the study population was $1.85 \pm 0.735 \times 10^{3}$ (range: $0.349-5.05$ ), it was 1.39 \pm 0.66 and $1.96 \pm 0.7 \times 10^{3}$ for patients with a CD4 count less than 200 and $\geq 200 / \mu \mathrm{L}$, respectively ( $p=0.000$ ), whereas there was no difference between the mean TLC in relation to gender, WHO clinical stages, ART status, and antiretroviral therapy (ART) regimens, which is in agreement with the study by Fekene et al. ${ }^{19}$ They also reported that lymphopenia was inversely related with the duration of HIV infection (higher prevalence observed in PLHIV diagnosed in the prior 6 months), which might be due to rapid viral replication and associated lymphocyte cell death occurring in the acute phase of HIV infection. Similar result holds for the duration of HAART treatment, lower prevalence observed in a group of patients with HAART duration longer than 6 months, which could due to the hematologic recovery after HAART treatment.

Thrombocytopenia was found to be higher in patients with CD4 count less than 299 cells $/ \mathrm{mm}^{3}$ and in patients not receiving ART therapy, which may probably be due to improvement 
in disease after the initiation of HAART. There were total of $15(11.3 \%)$ and 22 (16.5\%) HIV-positive patients having thrombocytopenia before and after HAART respectively, which was in accordance with the result reported by Erhabor et al. ${ }^{20}$ The mean platelet count at baseline was 197,991.04 \pm $58,985.7 / \mathrm{mm}^{3}$ and $202,205.22 \pm 75,219 / \mathrm{mm}^{3} 6$ months after HAART, with a mean difference of $-4,214.17$, which was not significant $(p>0.05)$. Dikshit et $\mathrm{al}^{3}$ and De Santis et al ${ }^{21}$ also showed only a limited increase in the number of thrombocytopenic cases in their cohort. The degree of thrombocytopenia was also found to be directly related to the degree of immunosuppression, as was confirmed in the study by Jost et $\mathrm{al}^{22}$ and Parinitha and Kulkarni. ${ }^{23}$ the mechanism involved may be increased platelet destruction (predominantly seen in early stages) and ineffective platelet production (more in late stages).

Pancytopenia was seen in 8 (5.9\%) patients and bicytopenia (thrombocytopenia and leucopoenia) was found in 7 (5.2\%) patients at baseline. Pancytopenia occurs frequently in HIV-1-infected patients, especially during advanced stages of the disease and pathogenesis involved may be impaired hematopoiesis and immune mediated. ${ }^{24}$ Cytopenia can result from HIV infection, opportunistic infections, or as a consequence of drug treatment. HIV can directly infect the BM cells, and the release of viral proteins is believed to have cytotoxic effects on marrow stem cells..$^{25,26}$

\section{Conclusion}

Peripheral blood cytopenia and immune paresis are common in HIV infection and increase in frequency with advancing disease. In our study, anemia was the most common hematological abnormality associated with HIV infection, especially normocytic normochromic anemia (more common with a low CD4 count). There was a significant improvement in $\mathrm{Hb}$, TLC, ANC, and ALC levels after HAART, with a positive correlation with CD4 count $(p<0.05)$. Thrombocytopenia was observed higher after HAART when compared to baseline. There was a positive correlation between platelet count and CD4 count. With this background, understanding the changes in the immunohematological profile trends during treatment can help prevent most of the adverse effects on HIV patients in our community.

\section{Conflict of Interest}

None declared.

\section{References}

1 Omodamiro OD, Jimoh MA. Haematological and biochemical changes in patients on anti-retroviral drugs. Am J Drug Deliv Therap 2017;4:1

2 Muluneh A, Fessahaye A. Hematologic abnormalities among children on HAART, in Jimma University Specialized Hospital, Southwestern Ethiopia. Ethiop J Health Sci 2009;19(2):83-89

3 Dikshit B, Wanchu A, Sachdeva RK, Sharma A, Das R. Profile of hematological abnormalities of Indian HIV infected individuals. BMC Blood Disord 2009;9:5-7
4 Akinbami A, Oshinaike O, Adeyemo T. Hematologic abnormalities in treatment-naïve HIV patients. Infect Dis Res Treat 2010;3:45-49

5 Behler C, Shade S, Gregory K, Abrams D, Volberding P. Anemia and HIV in the antiretroviral era: potential significance of testosterone. AIDS Res Hum Retroviruses 2005;21(3):200-206

6 Belperio PS, Rhew DC. Prevalence and outcomes of anemia in individuals with human immunodeficiency virus: a systematic review of the literature. Am J Med 2004;116(Suppl 7A) :27S-43S

7 Huang SS, Barbour JD, Deeks SG, et al. Reversal of human immunodeficiency virus type 1-associated hematosuppression by effective antiretroviral therapy. Clin Infect Dis 2000;30(3):504-510

8 Shah BS, Anudhakar SC. A study of hematological profile with special reference to thrombocytopenia in HIV infected persons with and without antiretroviral therapy. Int J Sci Res 2017;6(5):206-210

9 Wankah PN, Tagny CT, Mbanya DNS. Profile of blood cell abnormalities among antiretroviral therapy naïve HIV patients attending the Yaounde University Teaching Hospital, Cameroon. BMC Hematol 2014;14(1):15-19

10 Chauhan H, Shah P. Prospective, single centric study of hematological profile in HIV infected patients with correlation to CD4 count. Natl J Integr Res Med 2017;8(2):169-176

11 Assefa M, Abegaz WE, Shewamare A, Medhin G, Belay M. Prevalence and correlates of anemia among HIV infected patients on highly active anti-retroviral therapy at Zewditu Memorial Hospital, Ethiopia. BMC Hematol 2015;15:6-10

12 Semba RD, Gray GE. Pathogenesis of anemia during human immunodeficiency virus infection. J Investig Med 2001;49(3):225-239

13 Sullivan PS, Hanson DL, Chu SY, Jones JL, Ward JW. Epidemiology of anemia in human immunodeficiency virus (HIV)-infected persons: results from the multistate adult and adolescent spectrum of HIV disease surveillance project. Blood 1998;91(1):301-308

14 Thulasi R, Manimaran D, Hemanathan G, Afroz T, Sagar R. Hematological abnormalities in HIV infected individuals in correlation to CD4 counts and ART status. Asian J Med Sci 2016;7(4):14-18

15 Firnhaber C, Smeaton L, Saukila N, et al. Comparisons of anemia, thrombocytopenia, and neutropenia at initiation of HIV antiretroviral therapy in Africa, Asia, and the Americas. Int J Infect Dis 2010;14(12):e1088-e1092

16 Keshava HK, Manjunath R. Correlation between clinical profile, CD 4 count and total lymphocyte count in HIV infected Persons. J Med Dent Sci 2014;3(5):1264-1275

17 Murphy MF, Metcalfe P, Waters $\mathrm{AH}$, et al. Incidence and mechanism of neutropenia and thrombocytopenia in patients with human immunodeficiency virus infection. $\mathrm{Br}$ J Haematol 1987;66(3):337-340

18 Toure S, Gabillard D, Inwoley A, Seyler C, Gourvellec G, Anglaret X. Incidence of neutropenia in HIV-infected African adults receiving co-trimoxazole prophylaxis: a 6-year cohort study in Abidjan, Côte d'Ivoire. Trans R Soc Trop Med Hyg 2006;100(8):785-790

19 Fekene TE, Juhar LH, Mengesha CH, Worku DK. Prevalence of cytopenias in both HAART and HAART naïve HIV infected adult patients in Ethiopia: a cross sectional study. BMC Hematol 2018;18:8

20 Erhabor O, Ejele OA, Nwauche CA, Buseri FI. Some haematological parameters in human immunodeficiency virus (HIV) infected Africans: the Nigerian perspective. Niger J Med 2005;14(1):33-38 
21 De Santis GC, Brunetta DM, Vilar FC, et al. Hematological abnormalities in HIV-infected patients. Int $\mathrm{J}$ Infect Dis 2011;15(12):e808-e811

22 JostJ,TäuberMG,LüthyR,SiegenthalerW.HIV-associated thrombocytopenia. Schweiz Med Wochenschr 1988;118(6):206-212

23 Parinitha SS, Kulkarni MH. Haematological changes in HIV infection with correlation to CD4 cell count. Aust Med J 2012;5:157-162
24 Spivak JL, Bender BS, Quinn TC. Hematologic abnormalities in the acquired immune deficiency syndrome. Am J Med 1984;77(2):224-228

25 Opie J. Haematological complications of HIV infection. S Afr Med J 2012;102(6):465-468

26 Møller T, Hasselbalch HC. Hematological changes associated with human immunodeficiency virus (HIV-1) infection. Ugeskr Laeger 1993;155(19):1442-1446 